\title{
SYNTHESIS OF EOSIN Y-SENSITIZED Ag-TiO, NANO-HYBRID FOR OPTIMIZED PHOTOCATALYTIC DEGRADATION OF AQUEOUS CAFFEINE
}

\author{
MUKTAR MUSA IBRAHIMa, UMAR IBRAHIM GAYA Ia \\ ${ }^{a}$ Department of Pure and Industrial Chemistry, Faculty of Physical Sciences, Bayero University, \\ Kano, 700241 Kano, P.M.B. 3011, Kano State, Nigeria
}

\begin{abstract}
The visible light spectral response of titania nanoparticles synthesized by hybrid treatment of TiO, with silver dopant and Eosin Y-sensitizer was evaluated using caffeine, an emerging pollutant. The photocatalyst was characterized using scanning electron microscopy (SEM), x-ray diffraction (XRD), solid state UV/ Visible spectrometry and Fourier transform infrared spectrometry (FTIR). Upon sensitization and doping, downsizing, increase in surface area and redshift were observed without significant annihilation of the tetragonal anatase and rutile structures. Factors affecting the degradation of caffeine were studied using Taguchi orthogonal array model and optimized using a response surface methodology (RSM) based on faced-centered composite design (FCCD). Caffeine degradation under the conditions of the study was not affected significantly by temperature but $\mathrm{pH}$, initial concentration and catalyst concentration. Evidence for electron injection and red shift with sensitization was corroborated using quantum calculations at DFT/B3LYP level of the theory.
\end{abstract}

Keywords: $\mathrm{TiO}_{2}$; Photocatalysis; Caffeine; Taguchi; RSM; Doping.

\section{INTRODUCTION}

The past few decades have seen increasing concern over the presence of pharmaceuticals in aquatic environment. Caffeine is a naturally occurring purine alkaloid used in coffee, tobacco and tea as an analeptic ${ }^{1}$, and as enhancer in certain analgesics. This psychoactive substance is now recognized as emerging pollutant ${ }^{2}$ due to its endocrine disrupting property, recalcitrance and ubiquitous presence in aquatic environment ${ }^{3,4}$. The removal of caffeine by adsorption 5,6 and biodegradation 7 , has been achieved. These methods are however characterized by non-destructiveness and slow rate of removal.

Advanced oxidation Technologies (AOTs) driven by in-situ generated hydroxyl radicals, are now being intensively investigated due to their capacity for total oxidation of pollutants. By far, the removal of caffeine by AOTs such as ozonation, non-thermal plasma ${ }^{8}$ electro-Fenton and other Fenton-based oxidation methods, have been demonstrated ${ }^{9,10}$. However, the electrochemical and non-thermal plasma methods have the disadvantage of being energy intensive, and Fenton and photo-Fenton processes are predisposed to extreme $\mathrm{pH}$ dependence ${ }^{11}$. Accordingly, even though ozonation performed singly or in combination with other methods, has been effective in the removal of certain pharmaceuticals ${ }^{12}$, poor performance has been reported in the case of caffeine ${ }^{13,14}$. Rosal et al. ${ }^{15}$ found the ozonation of caffeine was especially rapid during the initial stage of the reaction period but declines thereafter to a much slower rate.

Among AOTs, photocatalysis has recorded significant success in effective caffeine removal. The process involves the utilization of holes and hydroxyl radicals harvested from sufficiently light-excited photoresponsive catalyst ${ }^{16}$. A few photocatalytic degradation studies on caffeine relied on $\mathrm{TiO}_{2}$ which has been considered to be chemostable and effective ${ }^{17}$. Nevertheless, large scale photocatalytic degradation is challenged by the inability of $\mathrm{TiO}_{2}$ to effectively absorb light in the visible region of the solar spectrum ${ }^{18}$, hence the search for visible light responsive catalysts or improved titania preparations.

(a)<smiles>Cn1c(=O)c2c(ncn2C)n(C)c1=O</smiles>

Dye-sensitization and doping constitute two prominent (coupling and band-gap modification) methods that successfully bridged this gap. In the latter, dye molecule is excited to produce electron which can be easily injected to the conduction band of the semiconductor for oxidation of oxygen molecule to superoxide $\left(\mathrm{O}^{\bullet-}\right)$ and hydroperoxide $\left(\mathrm{OOH}^{\bullet}\right)$ and hydroxyl radicals ${ }^{19}$. Dye-sensitization has been effective in various applications such as selective oxidation of alcohols ${ }^{20}$, photocatalytic degradation ${ }^{21}$ and solar cell ${ }^{22}$. Similarly, the visible light photoactivity of Ag-doped $\mathrm{TiO}_{2}$ has been established and dye sensitized coupled systems have been reported ${ }^{23,24}$. In this study, Eosin Y (EY) which was variously found to be an excellent sensitizer ${ }^{8,25}$ is applied to Agdoped $\mathrm{TiO}_{2}$ for the degradation of caffeine. The factors affecting degradation were optimized with the aid of Taguchi and face-centered central composite design. Changes in electronic absorption spectra of EY functionalized Ag-TiO via a carboxylate bridge was studied by the application of density functional theory (DFT) using hybrid functional (B3LYP).

\section{EXPERIMENTAL}

\subsection{Chemicals}

Titanium dioxide $(99.5 \%)$ and $\mathrm{H}_{2} \mathrm{SO}_{4}(98.08 \%)$ were purchased from Loba Chemie, India. Eosin Y dye $(99 \%)$ was supplied by Sigma Aldrich, Canada. Silver nitrate (90\%), caffeine $(99 \%)$ and $\mathrm{NaOH}(98 \%)$ were obtained from BDH, Poole, England. All chemicals were used as received from the manufacturers without further purification. Stock solutions were prepared using deionizer distilled water and used fresh. All experiments were carried out in a $30 \mathrm{~cm}$ long, 1L capacity, round bottom batch photoreactor previously described ${ }^{26}$, maintained at $299 \mathrm{~K}$. The visible light source was a W-lamp having luminous flux of $5250 \mathrm{~lm}$. This lamp was jacketed in cylindrical quartz glass of $7 \mathrm{~cm}$ diameter dipping down the reactor bottom. The effective volume of the photoreactor was $0.6 \mathrm{~L}$. The structure of caffeine and EY are shown in Fig. 1.

(b)<smiles>O=C(O)c1ccccc1C1=C2C=C(Br)C(O)=C(Br)C2Oc2c1cc(Br)c(O)c2Br</smiles>

Fig. 1: Molecular structures of caffeine (a), and EY (b), used in the study. 


\subsection{Synthesis of EY/Ag-TiO photocatalyst}

The doping of $\mathrm{TiO}_{2}$ with $\mathrm{Ag}$ was carried out using the photodeposition method reported by Wen et al. ${ }^{27}$. Specifically, $\mathrm{TiO}_{2}(5.0 \mathrm{~g})$ and $\mathrm{AgNO}_{3}(0.3-$ $2.1 \%$ mole ratio versus $\mathrm{TiO}_{2}$ ) were added into $100 \mathrm{ml}$ distilled water and was acidified using dilute $\mathrm{H}_{2} \mathrm{SO}_{4}$. The mixture was then stirred continuously under irradiation by a $25 \mathrm{~W}$ mercury lamp for 1 hour. The resulting precipitate was dried in oven for $12 \mathrm{~h}$ at $100^{\circ} \mathrm{C}$, ground and calcined at $400{ }^{\circ} \mathrm{C}$ for 4 hours and dried to obtain $\mathrm{Ag}-\mathrm{TiO}_{2}$. In order to sensitize this material, $1 \mathrm{~g}$ of the $\mathrm{Ag}-\mathrm{TiO}_{2}$ powder was transferred into a round bottom flask containing $0.1 \mathrm{M}$ ethanolic solution of the EY. The $\mathrm{pH}$ of the resulting suspension was adjusted to 7 using $\mathrm{H}_{2} \mathrm{SO}_{4}$ and $\mathrm{NaOH}(0.5 \mathrm{M}$ solutions) and the mixture was refluxed at 80 ${ }^{\circ} \mathrm{C}$ for $2 \mathrm{~h}$ so as to effectively bind the dye onto the $\mathrm{Ag}-\mathrm{TiO}_{2}$. The emerging solid fraction was filtered, washed three times with deionized water and $95 \%$ ethanol and then stored in dark container to avoid deactivation.

\subsection{Photocatalyst characterization}

In order to determine the crystal properties of the prepared titania catalysts, X-ray diffraction was performed using Philips X'Pert Pro diffractometer, using $\mathrm{Cu}-\mathrm{K} \alpha$ source $(\lambda=1.56877 \AA)$. The diffractometer was operated at $30 \mathrm{kV}$ and $30 \mathrm{~mA}$, over a $2 \theta$ range of $20^{\circ}$ to $120^{\circ}$. Morphology of the catalysts was recorded on LEICA stereo scan - 440 interfaced with Phoenix proxy energy dispersive $\mathrm{x}$-ray spectrometer. The FTIR spectra of the blank catalyst and dye sensitized was recorded using Agilent Cary 630 diamond attenuated total reflectance Fourier transform infrared spectrometer (ATR-FTIR). Band gap was calculated from electronic data recorded on Lambda 35 Perkin Elmer UV/ Vis spectrophotometer using Schuster-Kubelka-Munk relations. Spectrum was scanned over wavelength range of 200 to $800 \mathrm{~nm}$.

\subsection{Photocatalytic experiments}

In each experimental run, $400 \mathrm{ml}$ aqueous solution of desired amount of caffeine and $\mathrm{EY} / \mathrm{Ag}-\mathrm{TiO}_{2}$ photocatalyst were added to the photoreactor and the $\mathrm{pH}$ of the suspension was adjusted using $0.5 \mathrm{M} \mathrm{NaOH}$ and $\mathrm{H}_{2} \mathrm{SO}_{4}$. Aliquo was consistently taken at $0,30,50,70,90,110,130,150,170,190,210,230$ 250, 270 and $290 \mathrm{~min}$, which was centrifuged for $20 \mathrm{~min}$ at $1500 \mathrm{rpm}$. The supernatant liquid obtained was then filtered using $0.45 \mu \mathrm{m}$ cellulose nitrate filter. Residual caffeine levels were monitored by measuring absorbance at $271.56 \mathrm{~nm}$ using Perkin Elmer Lambda $25 \mathrm{UV}$-visible spectrophotometer. The percentage degradation efficiency was calculated as percent $(\% \mathrm{D})$ of the initial caffeine concentration using Eq.1.

$$
\% D=\frac{[\text { Caffeine }]_{o}-[\text { Caffeine }]_{t}}{[\text { Caffeine }]_{o}} \times 100
$$

Where $[$ Caffeine $] \mathrm{o}=$ initial caffeine concentration, [Caffeine $] \mathrm{t}=$ concentration of caffeine at irradiation time $t$.

\subsection{Optimization and kinetic profiling}

To optimize the photocatalytic degradation of caffeine, a three-level, three-variable, non-rotatable, face-centered central composite design (FCCD) was employed. The independent parameters were the $\mathrm{pH}(\mathrm{A}), \mathrm{EY} / \mathrm{Ag}-\mathrm{TiO}_{2}$ concentration (B) and initial caffeine concentration (C) in three levels (low, central, high) and three codes $(-1,0,+1)$ as displayed in Table 1 . In this FCCD, a total of 20 experiments $(\mathrm{N})$ were performed including 6 centre experiments as guided by the formula $\mathrm{N}=2^{\mathrm{n}}+2 \mathrm{n}+6$. Where $\mathrm{n}$ is the number of variables. Other variables such as agitation speed, light intensity, oxygen pressure and delivery volume were kept constant. The degradation efficiencies obtained from experiments were processed using Design Expert v6 to obtain the caffeine degradation model. In order to find the kinetic scheme consistent with the degradation of caffeine on $\mathrm{EY} / \mathrm{Ag}-\mathrm{TiO}$, experiments were run at optimal operating conditions and data were fitted into integrated rate equations. The profiles of possible background reactions such as adsorption on bare $\mathrm{TiO}_{2}$ and photolysis in absence of $\mathrm{TiO}_{2}$ were also examined. These were compared with photocatalysis over $\mathrm{EY}-\mathrm{TiO}_{2}, \mathrm{Ag}-\mathrm{TiO}_{2}, \mathrm{EY} / \mathrm{Ag}-\mathrm{TiO}_{2}$.

Table 1: Operating variables, levels and their codes.

\begin{tabular}{|c|c|c|c|c|}
\hline Experimental variables & $\begin{array}{c}\text { Notation } \\
\text { (and unit) }\end{array}$ & \multicolumn{3}{|c|}{ Levels (and codes) } \\
\hline $\mathrm{pH}$ & $\mathrm{A}$ & $3.0(-1)$ & $5.5(0)$ & $8.0(+1)$ \\
\hline Catalyst dose & $\mathrm{B}(\mathrm{g} / \mathrm{L})$ & $1.00(-1)$ & $1.75(0)$ & $2.50(+1)$ \\
\hline Caffeine concentration & $\mathrm{C}(\mathrm{mg} / \mathrm{L})$ & $10(-1)$ & $30(0)$ & $50(+1)$ \\
\hline
\end{tabular}

\subsection{Effect of operating parameters}

The effect of parameters was studied using four associated variables (initial caffeine concentration, catalyst dosage, $\mathrm{pH}$ and temperature) with minimum number of experiments, a three-levels-four-factor Taguchi orthogonal array (OA) $\mathrm{L}_{9}(3)^{4}$ design was performed using Minitab 17 statistical software package. Nine degradation experiments were conducted at three experimental levels $(1,2$, and 3$)$ of each parameter. The experimental factors with the strongest influence on the degradation of caffeine were determined based on the value of signal to noise ratio, and p-value. The experimental parameters and levels used for the Taguchi design are shown in Table 2.

Table 2: Experimental factors, levels and codes as used for the Taguch design.

\begin{tabular}{|c|c|c|c|c|c|}
\hline \multirow[t]{2}{*}{ Code } & \multirow[t]{2}{*}{ Experimental variables } & \multicolumn{3}{|c|}{ Levels in coded form } & \multirow[t]{2}{*}{ Units } \\
\hline & & 1 & 2 & 3 & \\
\hline A & Catalyst Dosage & 1 & 1.5 & 2 & $\mathrm{gL}^{-1}$ \\
\hline B & $\mathrm{pH}$ & 3 & 6 & 8 & \\
\hline $\mathrm{C}$ & Temperature & 35 & 45 & 65 & ${ }^{\circ} \mathrm{C}$ \\
\hline $\mathrm{D}$ & Caffeine Concentration & 10 & 30 & 50 & $\mathrm{mg} / \mathrm{L}$ \\
\hline
\end{tabular}

\subsection{Quantum chemical calculations}

All calculations were performed using Gaussian 09 program. The ground state geometries were optimized at DFT/B3LYP level of theory using a standard 6-316(d) basis set. The excitation energies and oscillator strength $(f)$ for singlet-singlet transition at optimized geometry by DFT calculations using the same hybrid functional and basis set.

\subsection{Catalyst characterization using XRD}

Rietveld profile refinement of the structures was performed using WINPLOTR package of FullProf suite version 3.0. The average crystalline size of EY-sensitized $\mathrm{TiO}_{2}$ and regular $\mathrm{TiO}_{2}$ photocatalyst were calculated using Williamson-Hall (Eq. 2) and the Scherer equation (Eq. 3). With the former, crystallite sizes were calculated from the y-intercept of the plot of $\beta \cos \theta$ against $\operatorname{Sin} \theta$ while the strain $(\varepsilon)$ was calculated from the slope.

$$
\beta \cos \theta=\frac{K \lambda}{\text { size }}+4 \varepsilon \times \sin \theta
$$

$$
\text { Crystallite size }=\frac{K \lambda}{\beta \cos \theta}
$$

Where $K$ is a constant $0.891, \lambda$ is the wavelength of $\mathrm{X}$-ray radiation, $\beta$ is the full width at half maximum intensity (FWHM) in radians, $\theta$ is diffraction angle at the position of peak maximum. Anatase and rutile contents of the titania photocatalysts were calculated using Spurr-Myers equation (Eq. 4) ${ }^{28}$ as it has been widely found applicable ${ }^{29,30}$.

$$
w_{A}=\frac{1}{1+1.26 \frac{I_{R}}{I_{A}}}
$$

Where $w_{\mathrm{A}}$ is the weight fraction of the anatase polymorph, $I_{R}$ is the intensity of diffraction peak for rutile and $I_{A}$ is the intensity of diffraction peak for anatase.

The lattice parameters ( $a, b$ and $c$ ) of $\mathrm{EY} / \mathrm{Ag}-\mathrm{TiO}_{2}$ photocatalyst were calculated using equation (5). The calculated values for the anatase and rutile polymorphs of the $\mathrm{EY}-\mathrm{Ag} / \mathrm{TiO}$, photocatalyst were compared to the unit cell parameters for standard anatase (JCPDS card no. 21-1272) and rutile (21-1276) polymorphs of $\mathrm{TiO}_{2}$

$$
\frac{1}{d^{2}}=\frac{h^{2}+k^{2}}{a^{2}}+\frac{l^{2}}{c^{2}}
$$

Where $d$ is the spacing between planes in atomic lattice. The $h, k$ and $l$ are the miller indices, while $a, b$ and $c$ are lattice parameters. 


\subsection{RESULTS AND DISCUSSION}

\subsection{Photocatalyst characterization}

\subsubsection{XRD analysis}

Crystallite size and structure of materials constitute important factors that can dictate the efficiency of photocatalyst. An overlay of the diffraction profiles of the $\mathrm{EY} / \mathrm{Ag}-\mathrm{TiO}_{2}$ and regular $\mathrm{TiO}_{2}$ photocatalyst are displayed in Fig. 2. The sensitized $\mathrm{TiO}_{2}$ material shows anatase peaks at $2 \theta$ (and planes) $=25.88^{\circ}(101), 39.47^{\circ}(004), 46.72^{\circ}(200), 73.87^{\circ}(215)$ and rutile peaks (and planes) at $27.02^{\circ}(110), 39.47^{\circ}(111), 54.46^{\circ}(211), 64.03^{\circ}(310)$. Even though XRD pattern of photodeposited silver on $\mathrm{TiO}_{2}$ does not modify the crystal structure of $\mathrm{TiO}_{2}$, so does not usually show metallic silver peaks corresponding to planes $111\left(39.76^{\circ}\right.$ ) and $220\left(67.71^{\circ}\right)^{27,31,32}$ presumably due to being below visibility limit of XRD ${ }^{33}$, the presence metallic silver is herein evidenced by the presence of a prominent diffraction peak at $34.12^{\circ}$ corresponding to $\mathrm{Ag}(111)$ reflection. The bare $\mathrm{TiO}_{2}$ (Fig. 2) displayed strong anatase peaks at $38.26^{\circ}(004), 48.49^{\circ}(200), 69.11^{\circ}(116) 75.44^{\circ}(215)$, and rutile peaks at $41.72^{\circ}(111), 54.33^{\circ}(211)$ and $63.09^{\circ}(002)$. The rutile and anatase peaks and planes correspond to those of pure phases reported in literature ${ }^{34,35}$.

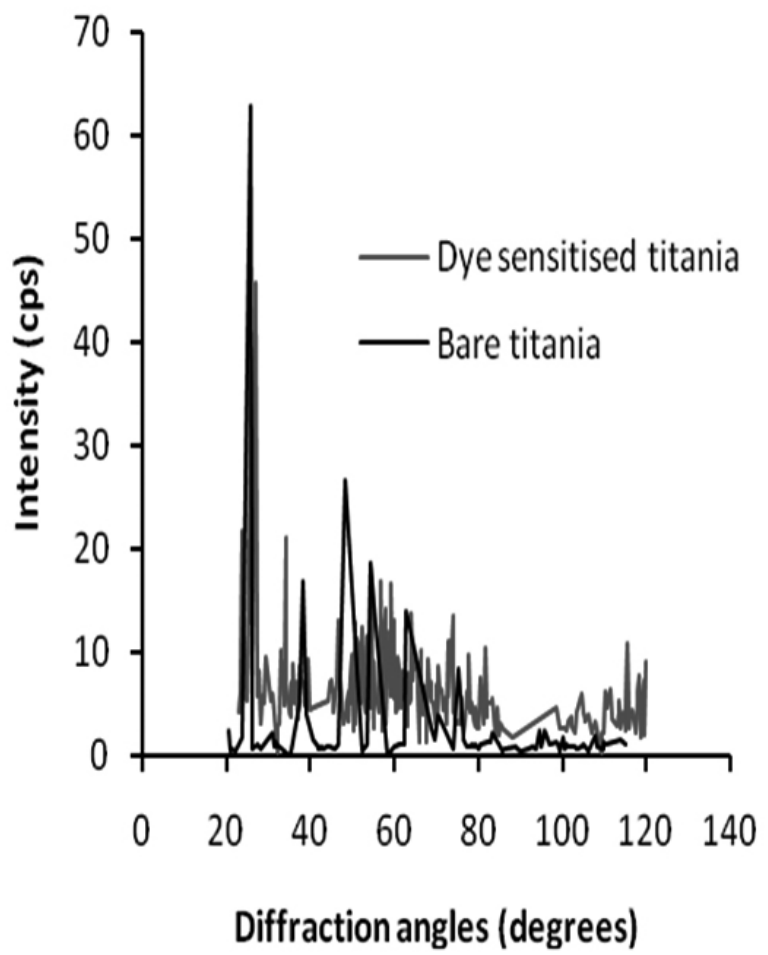

Fig. 2: Overlay of diffractograms showing XRD peaks of EY/Ag- $\mathrm{TiO}_{2}$ (coloured red) and bare $\mathrm{TiO}_{2}$ (black).
The unit cell parameters of the EY-sensitized $\mathrm{Ag}$ - $\mathrm{TiO}$, were calculated (Table 3) based on anatase lattice planes 101 and 004 and rutile reflections 111 and 211. It would be seen that the values displayed in Table 3 agree with the standard lattice parameters for pure anatase $(\mathrm{a}=0.3784 \mathrm{~nm}$ and $\mathrm{c}=0.9515$ $\mathrm{nm})$ and pure rutile $(\mathrm{a}=0.4536 \mathrm{~nm} \text { and } \mathrm{c}=0.29587 \mathrm{~nm})^{37}$. This confirms that the EY/Ag-TiO contains a mixture of anatase and rutile polymorph in their tetragonal structures. The crystal structure properties of the EY/Ag-TiO, and regular $\mathrm{TiO}_{2}$ are shown in Table 3. Rietveld analysis of the diffraction data showed the exclusive presence of only the anatase and rutile peaks in the bare $\mathrm{TiO}_{2}$. The mass percentages of anatase and rutile polymorphs in the regular $\mathrm{TiO}_{2}$ were 97.6 and $2.32 \%$, respectively. Basically, mixture of anatase and rutile $\mathrm{TiO}$, polymorphs has been reported to have superior photocatalytic ability than either polymorph in its pure form as it is in the case of the popular Degussa P-25 with $70-80 \%$ anatase and rutile rest ${ }^{36,38}$. The XRD profile of EY-sensitized Ag-TiO (Fig. 2) shows amorphousness resulting from the sensitization with $73.9 \%$ anatase, and $26.1 \%$ distributed among rutile and amorphous material. Unless an isolation of the polymorphs is performed, it will be erroneous to rule out the presence of amorphous $\mathrm{TiO}_{2}{ }^{38}$.

Table 3: Crystal structure properties of the as-synthesised $\mathrm{EY} / \mathrm{Ag}-\mathrm{TiO}_{2}$.

\begin{tabular}{|c|c|c|}
\hline Property & \multicolumn{2}{|c|}{ EY/Ag-TiO } \\
\hline & Anatase unit & Rutile unit \\
\hline Crystal structure & Tetragonal & Tetragonal \\
\hline Lattice structure (nm) & $\mathrm{a}=0.370$ & $\mathrm{a}=0.453$ \\
\hline & $\mathrm{c}=0.947$ & $\mathrm{c}=0.295$ \\
\hline Unit cell volume $\left(\mathrm{nm}^{3}\right)$ & 0.136 & 0.258 \\
\hline
\end{tabular}

The average crystallite size of the $\mathrm{EY} / \mathrm{Ag}-\mathrm{TiO}_{2}$ was calculated using Scherer equation. Because values obtained (Table 4 ) were slightly above the level which particles are expected to show strain $(<50 \mathrm{~nm})$, values were also calculated from more suited Williamson-Hall profile (supplementary materials, Fig. A-1 and Fig. A-2). In both cases, downsizing of the $\mathrm{TiO}_{2}$ particles was observed after sensitization, which may be attributed to large degree of distortions ${ }^{39}$. The Williamson particle size dropped from $138 \mathrm{~nm}$ to $69.32 \mathrm{~nm}$.

3.1.2 Scanning electron microscopy

The SEM images of the bare $\mathrm{TiO}_{2}, \mathrm{Ag}$-deposited $\mathrm{TiO}_{2}$ and $\mathrm{EY}-\mathrm{Ag} / \mathrm{TiO}{ }_{2}$ photocatalyst are shown in Fig. 3. It can be seen that the surfaces of the particles of $\mathrm{EY}-\mathrm{Ag} / \mathrm{TiO}_{2}$ do not differ markedly from those the bare titania, being both rough and porous. The dark spots on the SEM micrograph are due to open pores on the surface of the catalysts. Estimated grain sizes from the figures show that the dye sensitized photocatalyst may have smaller particle size than regular $\mathrm{TiO}_{2}$ photocatalyst.

Table 4: Particle size estimated using Debye Scherer and Williamson-Hall methods.

\begin{tabular}{|c|c|c|c|c|c|}
\hline \multirow{2}{*}{ Catalyst } & \multicolumn{2}{|c|}{ Particle size (nm) } & \multicolumn{2}{c|}{ Polymorphs (\%) } & Specific surface area $\left(\mathrm{m}^{2} \mathrm{~g}^{-1}\right)$ \\
\hline & Debye-Scherer & Williamson-Hall & Anatase & Rutile \\
\hline $\mathrm{TiO}_{2}$ & 79.1 & 138.64 & 97.6 & 2.32 & 24.32 \\
\hline $\mathrm{EY}-\mathrm{Ag} / \mathrm{TiO}_{2}$ & 58.3 & 69.32 & 73.9 & ca $26.1 *$ & 17.92 \\
\hline
\end{tabular}

*The rutile content depends on the amount of amorphous $\mathrm{TiO}_{2}$ possibly present. 


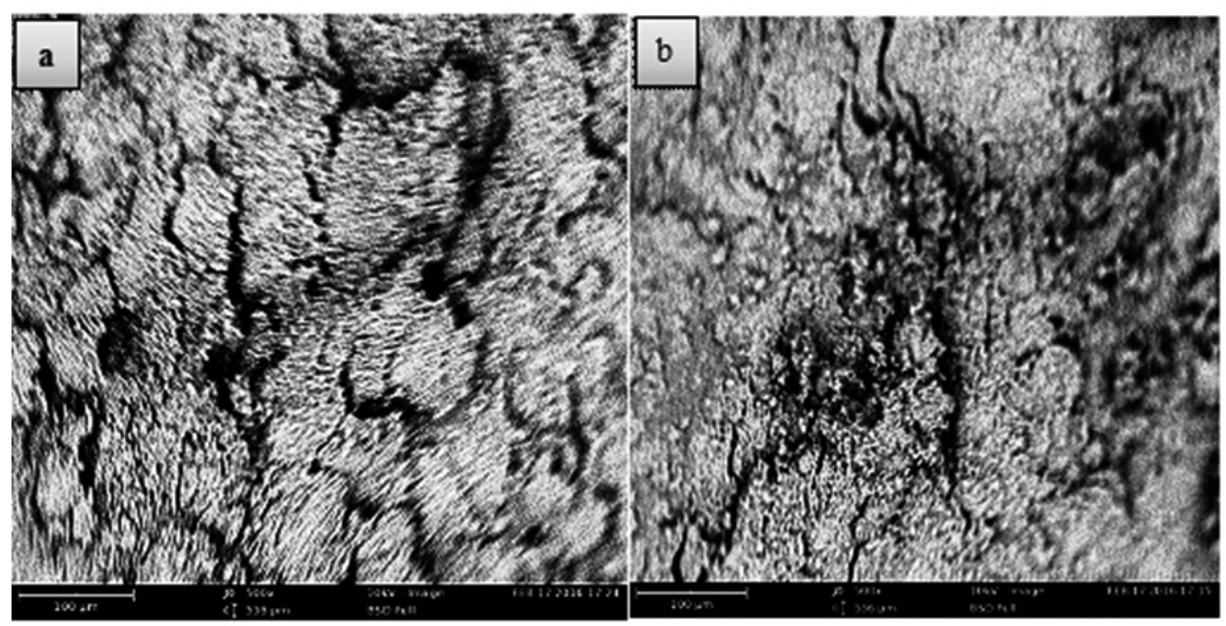

Fig. 3: The SEM images of (a) $\mathrm{Bare}^{\mathrm{TiO}_{2}}$ (c) $\mathrm{EY}-\mathrm{Ag} / \mathrm{TiO}{ }_{2}$.

3.1.3 Fourier transform infra-Red (FTIR) analysis

In order to confirm that Eosin functionalities were used in the sensitization of $\mathrm{Ag}-\mathrm{TiO}_{2}$, FTIR spectrum of the EY (Fig. 4a) and the EY/Ag-TiO were recorded (Fig. 4b). In the EY spectrum the broad absorption peak at $329 \mathrm{~cm}^{-1}$ is due to $\mathrm{OH}$ from $-\mathrm{COOH}$ group of the dye. The peaks at $717 \mathrm{~cm}^{-1}$ and $1175 \mathrm{~cm}^{-1}$ are due to $\mathrm{C}-\mathrm{Br}$ and $\mathrm{C}-\mathrm{O}-\mathrm{C}$ groups respectively ${ }^{40}$. The vibrational frequency for ester functional group at $1700 \mathrm{~cm}^{-1}$ was absent in the spectrum of dye sensitized photocatalyst. This indicates that the $\mathrm{TiO}_{2}$ photocatalyst was linked to the Eosin Y dye molecules via a carboxylate linkage. This supposition was confirmed by the presence of a vibrational peak for carboxylic carbonyl group at $1655 \mathrm{~cm}^{-1}$. Furthermore, it was observed that the carboxylate carbonyl group of Eosin Y dye shift from $1607 \mathrm{~cm}^{-1}$ to $1655 \mathrm{~cm}^{-1}$ in the dye sensitized catalyst. Upon sensitization, these peaks were all suppressed which is an indication of bonding of EY moieties to the $\mathrm{Ag}-\mathrm{TiO}_{2}$ (Fig. 4b). The peak at $\approx 660 \mathrm{~cm}^{-1}$ is due to Ti-O-Ti. Other peaks due to bonding to $\mathrm{EY} / \mathrm{Ag}-\mathrm{TiO}_{2}$ are expected to appear at lower ranges. The FTIR spectrum of the unsensitized $\mathrm{TiO}_{2}$ (Fig. A-3, supplementary materials) did not differ from that of the sensitized $\mathrm{TiO}_{2}$, both showing no organic functional groups of the sensitizer.
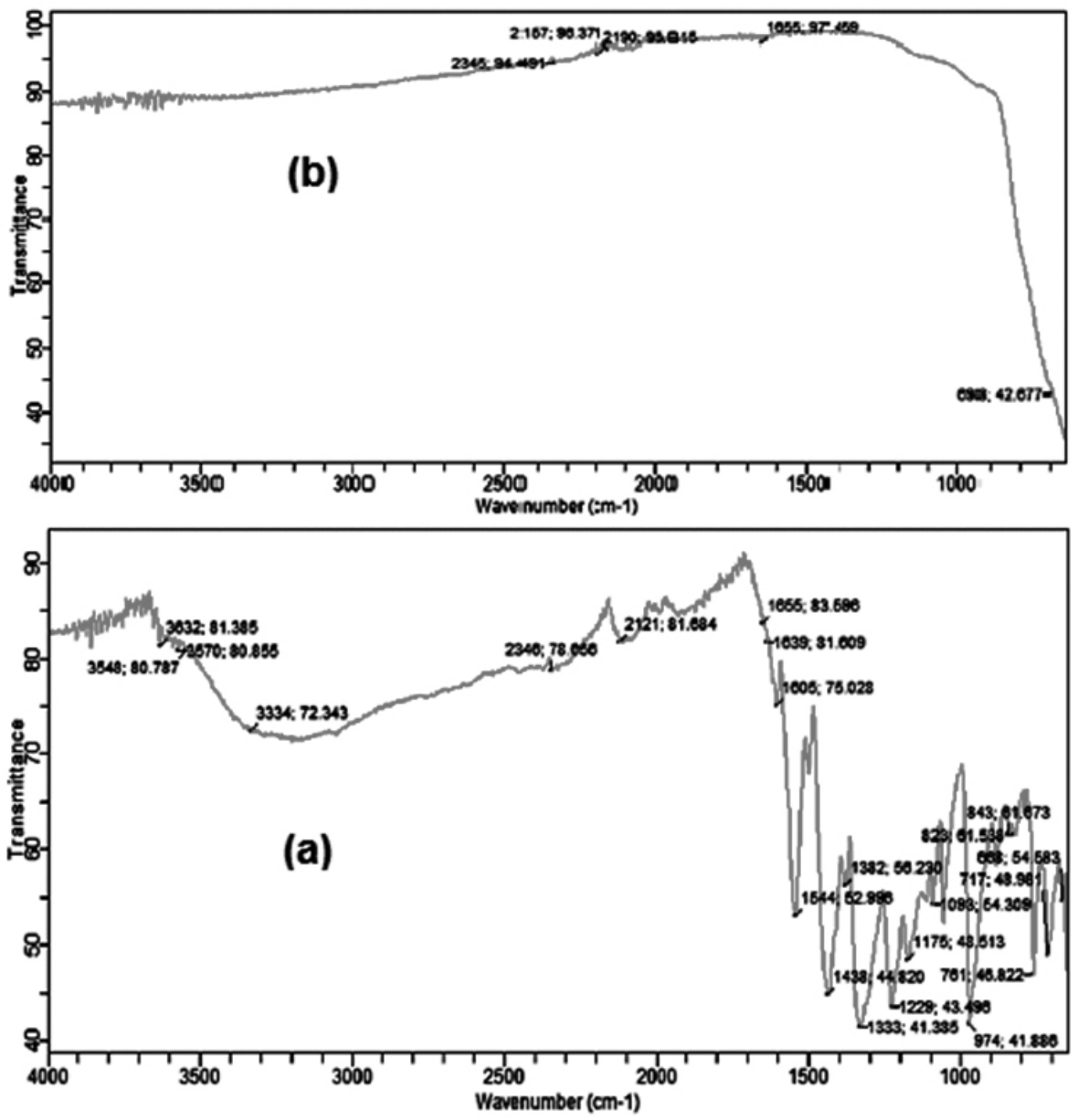

Fig. 4: FTIR spectra of (a) EY/Ag-TiO (b) EY. 
3.1.4 Band gap determination

In order to determine the wavelength of light necessary for the excitation of the $\mathrm{EY}-\mathrm{Ag} / \mathrm{TiO}_{2}$, band gap energy was calculated from absorption data using Schuster-Kubelka-Munk's relational expression (Eq. 6).

$$
[h v \alpha]^{\frac{1}{n}}=A\left(h v-E_{g}\right)
$$

Where $h$ is the Planck's constant, $v$ is the frequency of vibration, $\alpha$ is the absorption coefficient, $E_{g}$ is the band gap and $A$ is a proportionality constant.
If scattering is insignificant, the term $h v \alpha$ is proportional to a function of reflectance $[F(R) h v]$. Since the direct allowed sample transition is used in this experiment, the value of the denominator of the exponent $\mathrm{n}=1 / 2$. The bandgap corresponds to the the intercept of the plot of $(h v \alpha)^{2}$ or $[F(R) h v]^{2}$ against $h v$ (Fig. 5). The bandgap the $\mathrm{EY}-\mathrm{Ag} / \mathrm{TiO}_{2}$ photocatalyst was found to be 3.06 $\mathrm{eV}$ (Fig. 5a) which stands in the vicinity of that of rutile $\mathrm{TiO}_{2}(3.05 \mathrm{eV})^{41}$. A redshift is readily observed from the band gap of the commercial $\mathrm{TiO}_{2}$ (3.25) (Fig. 5b) which shows that more of the visible light can now be absorbed by the sensitized photocatalyst.
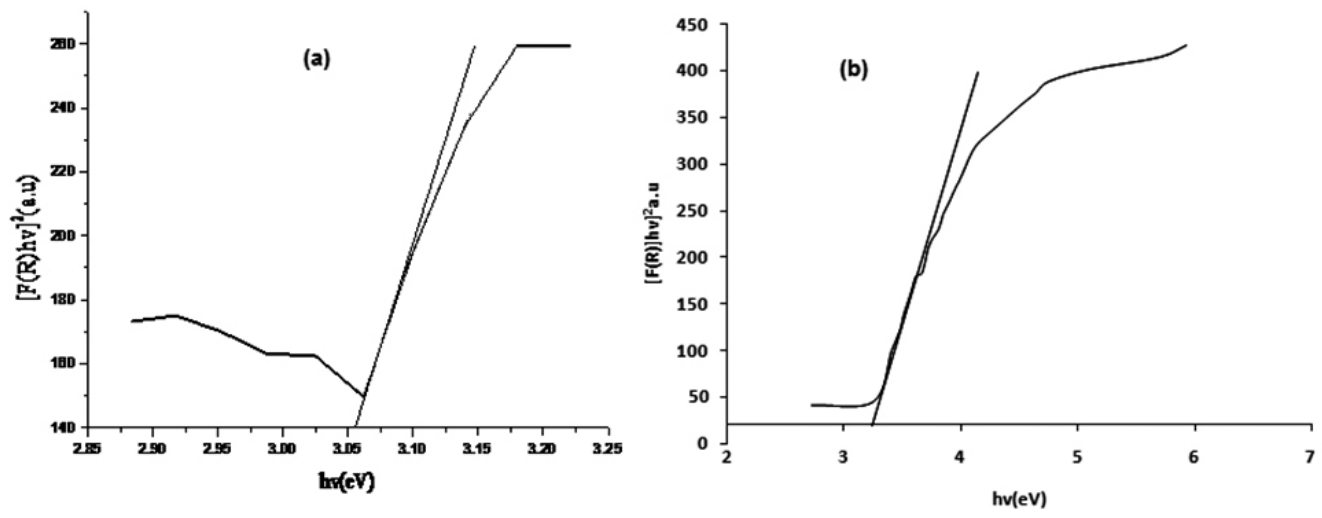

Fig. 5: Tauc's plot for (a) $\mathrm{EY}-\mathrm{Ag} / \mathrm{TiO}_{2}$, (b) Bare $\mathrm{TiO}_{2}$

\subsection{Optimizations of experiments}

4.5.1 Amount of dopant in the catalyst

The effect of the amount of silver deposited EY-TiO, photocatalyst on the degradation of caffeine was studied in range of $0.3-2.1 \%$ of Ag:Ti molar ratio (Fig. 6). The increase in the amount of the Ag load from 0.3 to $1.5 \%$ steadily increases the photocatalytic degradation efficiency of caffeine. Decline in the degradation efficiency was observed at molar ratios above $1.5 \%$. Hence, the optimal Ag loading used in this study is $1.5 \%$. This finding is in agreement with the study of photocatalytic degradation of methyl orange reported by Wen et al. ${ }^{27}$ in which best degradation efficiency was obtained when $\mathrm{TiO}_{2}$ was loaded with $1.6 \% \mathrm{Ag}$.

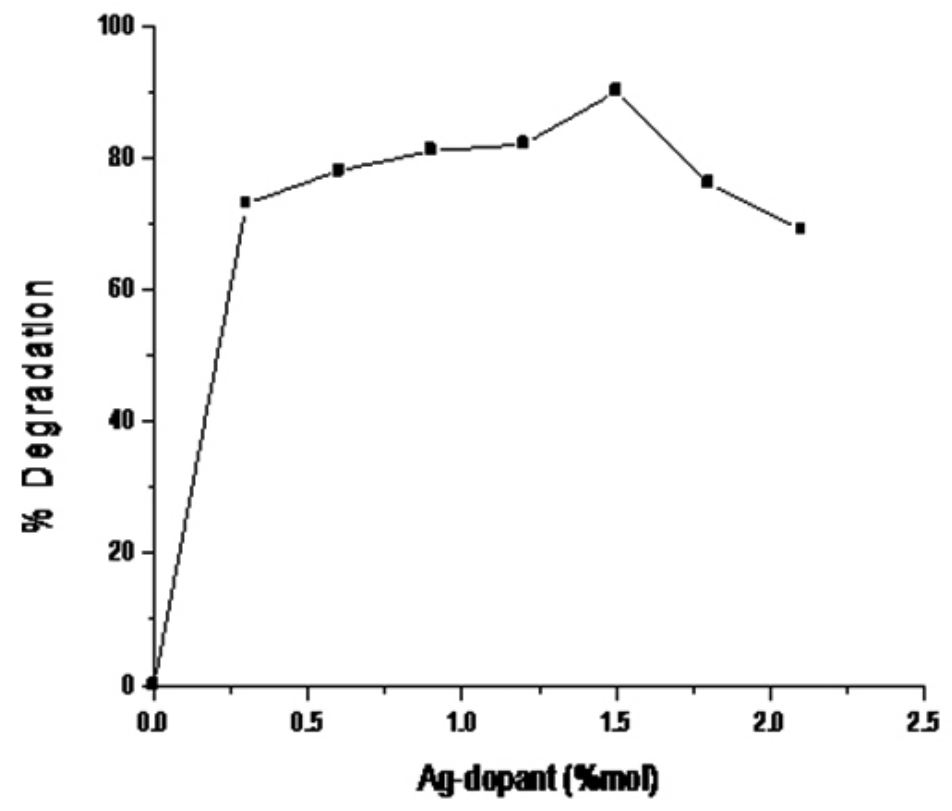

Fig. 6: Graph showing the effect Ag addition on the performance of the EY/ $\mathrm{Ag}-\mathrm{TiO}_{2}$ catalyst.

4.5.2 Response surface methodology (RSM)

The values of degradation efficiency obtained from experiment (\% D) were processed using response surface module to obtain statistically valid predicted values. These values for all the FCCD experiments are listed in Table 5. From the table it can be seen that the there is good correlation between the experimental and predicted degradation efficiencies as attested by linear normal plot of residuals (Fig. A-4, supplementary materials). Majority of the points on the normal probability plot lie roughly on a straight line, so it can be concluded that the estimated effects are the real and differ markedly from noise. 
J. Chil. Chem. Soc., 64, No 1 (2019)

Table 5: Efficiency of different combination of levels of factors for caffeine removal.

\begin{tabular}{|c|c|c|c|c|c|}
\hline \multirow{2}{*}{ Run } & \multicolumn{3}{|c|}{ Factors } & \multicolumn{2}{|c|}{ Degradation efficiency, \% D } \\
\hline & $\mathrm{pH}(\mathrm{A})$ & Catalyst (B; g/L) & Caffeine $(\mathrm{C} ; \mathrm{mg} / \mathrm{L})$ & (Experimental) & (Predicted) \\
\hline 1 & $3.0(-1)$ & $2.5(+1)$ & $50(+1)$ & 50 & 53.15 \\
\hline 2 & $8.0(+1)$ & $2.5(+1)$ & $50(+1)$ & 82 & 76.05 \\
\hline 3 & $8.0(+1)$ & $1.75(0)$ & $30(0)$ & 90 & 78.20 \\
\hline 4 & $8.0(+1)$ & $2.5(+1)$ & $10(-1)$ & 92 & 107.35 \\
\hline 5 & $3.0(-1)$ & $1.75(0)$ & $30(0)$ & 44 & 65.80 \\
\hline 6 & $3.0(-1)$ & $2.5(+1)$ & $10(-1)$ & 74 & 63.45 \\
\hline 7 & $8.0(+1)$ & $1.00(-1)$ & $10(-1)$ & 87 & 81.35 \\
\hline 8 & $5.5(0)$ & $1.75(0)$ & $30(0)$ & 90 & 84.00 \\
\hline 9 & $5.5(0)$ & $1.75(0)$ & $50(+1)$ & 60 & 73.10 \\
\hline 10 & $5.5(0)$ & $1.75(0)$ & $30(0)$ & 73 & 84.00 \\
\hline 11 & $5.5(0)$ & $1.75(0)$ & $30(0)$ & 87 & 84.00 \\
\hline 12 & $5.5(0)$ & $1.75(0)$ & $30(0)$ & 95 & 84.00 \\
\hline 13 & $3.0(-1)$ & $1.00(-1)$ & $10(-1)$ & 76 & 79.45 \\
\hline 14 & $5.5(0)$ & $1.00(-1)$ & $30(0)$ & 76 & 81.00 \\
\hline 15 & $5.5(0)$ & $1.75(0)$ & $30(0)$ & 86 & 84.00 \\
\hline 16 & $5.5(0)$ & $1.75(0)$ & $10(-1)$ & 97 & 84.00 \\
\hline 17 & $5.5(0)$ & $2.5(+1)$ & $30(0)$ & 96 & 87.00 \\
\hline 18 & $8.0(+1)$ & $1.00(-1)$ & $50(+1)$ & 40 & 48.05 \\
\hline 19 & $5.5(0)$ & $1.75(0)$ & $30(0)$ & 80 & 84.00 \\
\hline 20 & $3.0(-1)$ & $1.00(-1)$ & $50(+1)$ & 85 & 67.15 \\
\hline
\end{tabular}

The relationship between the degradation efficiency of caffeine (\% D) under the interplay of the independent variables of the study $\mathrm{A}$, B and $\mathrm{C}$ is best described by the reduced quadratic model described by equation (7), in which the quadratic contributions of catalyst and caffeine concentration terms varnish.

$\% \mathrm{D}=84+6.2 \mathrm{~A}+3 \mathrm{~B}-10.9 \mathrm{C}-12 \mathrm{~A}^{2}+10 \mathrm{AB}-5.25 \mathrm{AC}+0.5 \mathrm{BC}$

The response surface model was adjudged to be significant based on the analysis of variance (ANOVA) shown in Table 6. The model's Prob $>$ F in the table is less than 0.05 and this shows that predicted degradation efficiencies are not influenced at $95 \%$ confidence level. Similarly, the Prob > F of $6.91 \%$ for the lack-of-fit value indicates very low probability of occurrence due to noise.

Table 6: Analysis of variance for the response surface reduced quadratic model.

\begin{tabular}{|c|c|c|c|c|c|c|}
\hline Source & $\begin{array}{l}\text { Sum of } \\
\text { squares }\end{array}$ & $\mathrm{DF}$ & Mean square & F-value & Prob $>$ F & Remark \\
\hline Model & 3487.00 & 7 & 498.14 & 2.95 & 0.0479 & Significant \\
\hline$A$ & 384.40 & 1 & 384.40 & 2.28 & 0.1569 & \\
\hline$B$ & 90.00 & 1 & 90.00 & 0.53 & 0.4790 & \\
\hline$C$ & 1188.10 & 1 & 1188.10 & 7.05 & 0.0210 & \\
\hline$A^{2}$ & 720.00 & 1 & 720.00 & 4.27 & 0.0611 & \\
\hline$A B$ & 882.00 & 1 & 882.00 & 5.23 & 0.0411 & \\
\hline$A C$ & 220.50 & 1 & 220.50 & 1.31 & 0.2751 & \\
\hline$B C$ & 2.00 & 1 & 2.00 & 0.012 & 0.9151 & \\
\hline Residual & 2023.00 & 12 & 168.58 & & & \\
\hline Lack of Fit & 1724.17 & 7 & 246.31 & 4.12 & 0.0691 & Not significant \\
\hline Pure Error & 298.83 & 5 & 59.77 & & & \\
\hline Cor Total & 5510.00 & 19 & & & & \\
\hline
\end{tabular}

Some measures of dispersion associated with the model of this study are listed in (Table A-1 of supplementary materials). From the Table, the PRESS value of the model of 17,967 indicates extremely high signal-to-noise ratio.

The minimum adequate precision desirable in any experiment is a value $>4$ In this study, the adequate precision is 7.221 which confirms adequate model discrimination. The global effect of the operating variables are presented by the 3D response surfaces in Fig. 7. From Fig. 7a, there is synergy between catalyst concentration and $\mathrm{pH}$ as values as they are increased towards the intermediate levels $(1.75 \mathrm{~g} / \mathrm{L}$ and $\mathrm{pH} 5.5$, repectively) and maximum degradation efficiency up to $87 \%$ can be reached. The figure shows that alternating any of the 
combinations of levels would result in low degradation efficiency. The same observation was made in the case of interplay of $\mathrm{pH}$ and caffeine concentration (Fig. 7b). However, in the case of catalyst and caffeine concentration (Fig. 7c), the degradation efficiency decreased as the amount of these variables is increased. This can be attributed to the screening of light by these parameters as their values are increased.
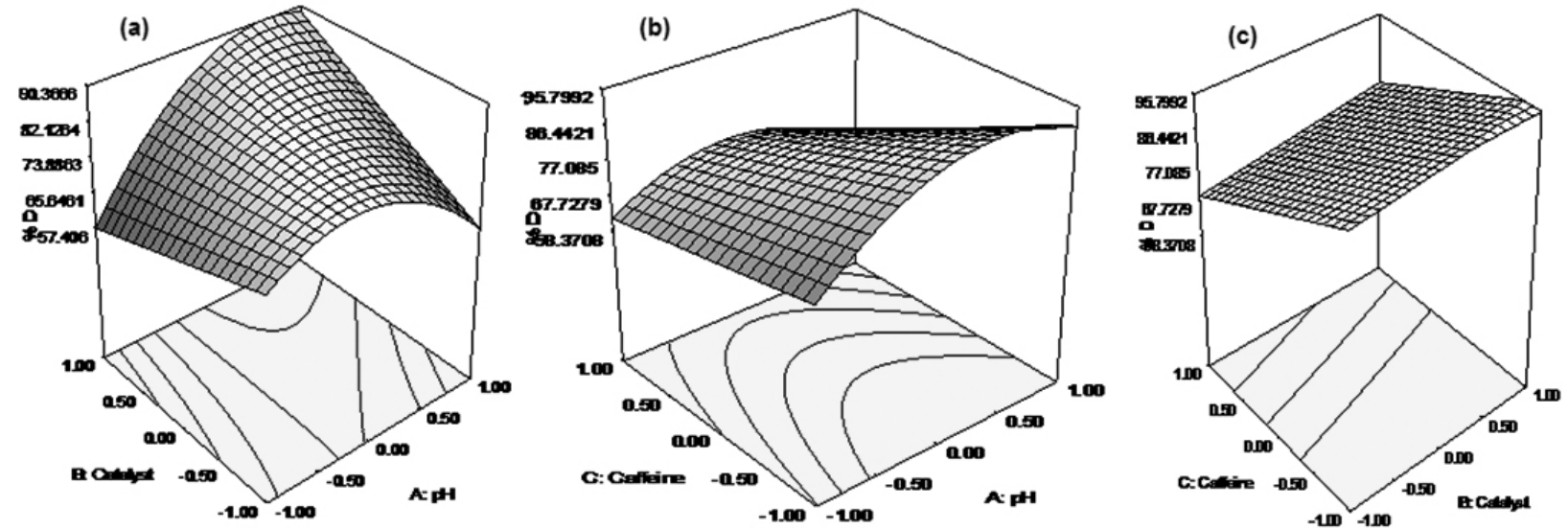

Fig. 7: Response surfaces for (a) $\mathrm{pH}$ and $\mathrm{EY} / \mathrm{Ag}-\mathrm{TiO}_{2}$ concentration (b) $\mathrm{pH}$ and caffeine concentration (c) caffeine and catalyst concentration.

\subsubsection{Taguchi optimization of experiments}

In this study, Taguchi design was also utilized for process optimization. The results of Taguchi method have the advantages of high reproducibility, reduced number of experiments and easy comprehension. Performance of set of variables the Taguchi experiments were measured based on signal-to-noise ratio, a response parameter that takes into account process mean and variance ${ }^{42}$. Experimental factors with signal to noise ratio larger than the mean effect were considered as the significant factors.

Table 7: Taguchi $\mathrm{OA} \mathrm{L}_{9}(3)^{4}$ design Matrix.

\begin{tabular}{|c|c|c|c|c|c|}
\hline Experiment & $\mathrm{A}$ & $\mathrm{B}$ & $\mathrm{C}$ & $\mathrm{D}$ & \% Degradation \\
\hline 1 & 1 & 1 & 1 & 1 & 47 \\
\hline 2 & 1 & 2 & 2 & 2 & 75 \\
\hline 3 & 1 & 3 & 3 & 3 & 69 \\
\hline 4 & 2 & 1 & 2 & 3 & 65 \\
\hline 5 & 2 & 2 & 3 & 1 & 90 \\
\hline 6 & 2 & 3 & 1 & 2 & 52 \\
\hline 7 & 3 & 1 & 3 & 2 & 92 \\
\hline 8 & 3 & 2 & 1 & 3 & 97 \\
\hline 9 & 3 & 3 & 2 & 1 & 37 \\
\hline
\end{tabular}

Table 7 shows the Taguchi design matrix consisting nine experiments at combination of three levels of four factors (EY-Ag-TiO ${ }_{2}$ dose, $\mathrm{A} ; \mathrm{pH}$, $\mathrm{B}$; temperature, $\mathrm{C}$ and caffeine concentration, $\mathrm{D})$ with each corresponding performance presented as percent degradation. The corresponding results of Taguchi experimental design are shown in Table 8. The influence of experimental factors was ranked based on the difference between the maximum and the minimum $\mathrm{S} / \mathrm{N}$ ratios for a particular experimental factor, denoted as delta. Based on this, the order of influence is $\mathrm{pH}(\mathrm{B})>$ initial caffeine concentration (D) $>\mathrm{EY} / \mathrm{Ag}-\mathrm{TiO}_{2}$ dosage (A) $>$ temperature (C). In actual fact, it is well known that photocatalytic reactions are not affected by minor variations in temperature ${ }^{41}$. Similarly, the unrivalled dependence of the photocatalytic process on $\mathrm{pH}$ has variously been reported ${ }^{43}$ as it affects the adsorption equilibrium. From Table 8, the optimal levels for each experimental factors obtained according to Taguchi's "the larger the better" criteria are accordingly, $2 \mathrm{~g} / \mathrm{L}$ catalyst dosage, $\mathrm{pH} 6,45^{\circ} \mathrm{C}$ temperature and $50 \mathrm{mg} / \mathrm{L}$ initial caffeine concentration. The optimum $\mathrm{pH}$ attained roughly matches the $\mathrm{pH}$ at point of zero charge of $\mathrm{TiO}_{2}\left(\mathrm{pH}_{\mathrm{pzc}}=6.25\right)^{36}$. The implication is that $\mathrm{pH}$ will affect the adsorption equilibrium when exceedingly low or high resulting in poor degradation.
Table 8: Signal to noise $(\mathrm{S} / \mathrm{N})$ ratio response table for degradation of caffeine.

\begin{tabular}{|c|c|c|c|c|}
\hline Level & $\mathrm{A}(\mathrm{g} / \mathrm{L})$ & $\mathrm{B}$ & $\mathrm{C}\left({ }^{\circ} \mathrm{C}\right)$ & $\mathrm{D}(\mathrm{mg} / \mathrm{L})$ \\
\hline 1 & 37.61 & 37.40 & 36.94 & 37.81 \\
\hline 2 & 36.49 & 39.27 & 37.49 & 36.29 \\
\hline 3 & 37.08 & 34.51 & 36.75 & 37.27 \\
\hline Delta & 1.12 & 4.76 & 0.73 & 1.72 \\
\hline Rank & 3 & 1 & 4 & 2 \\
\hline
\end{tabular}

The influence of parameters in the degradation of caffeine can further be explained based on main effect. Main effect is considered present when the mean response changes across the level of experimental variables. The sign of the main effect indicates the direction of the effect. Fig. 8 shows that the temperature has negative effect on the photocatalytic degradation process whereas catalyst dosage and initial caffeine concentration have positive effect. Temperature has negligible consequence on the photodegradation kinetics because it has almost no contribution to the activation energy of $\mathrm{TiO}_{2}$ due to its relatively high band gap ${ }^{41}$. Undoubtedly, increase in temperature might increase the kinetic energy of Eosin Y molecules, thus disrupting the sensitization linkages between EY molecules and $\mathrm{TiO}_{2}$. The positive effect of catalyst loading might be attributable to increase in the number of site available for generation of the free radicals responsible for the photodegradation process.

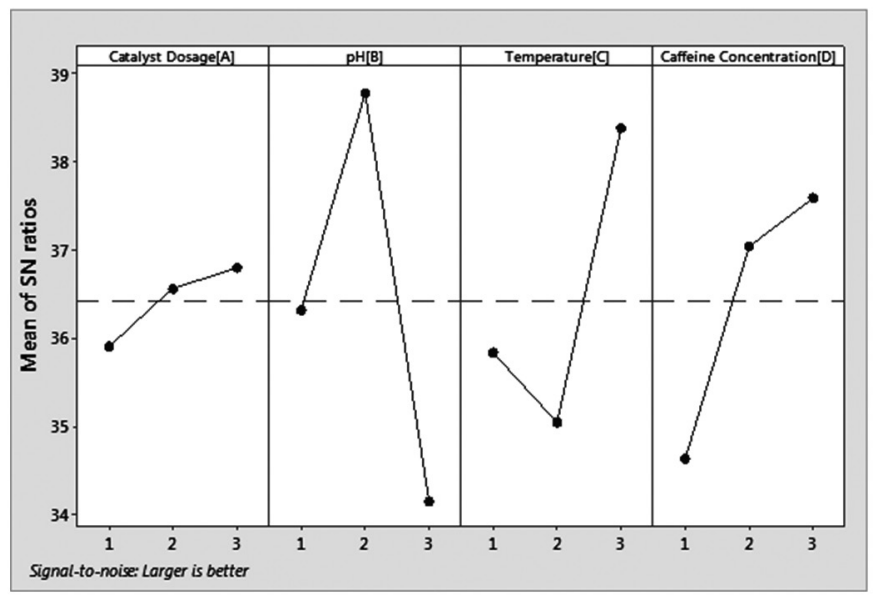

Fig. 8: Main effect plots for the $\mathrm{S} / \mathrm{N}$ ratios depicting the effect of $\mathrm{pH}$, catalyst dosage, temperature and initial concentration of caffeine. 
The analysis of variance (ANOVA) (Table 9) was conducted to further investigate which design parameter significantly affects the degradation of caffeine. The $\mathrm{p}$-value for each design parameter was chosen to dictate decisions as widely recommended. Examination of Table 9 suggests that temperature has negligible influence in the rate of degradation of caffeine with the highest $\mathrm{p}$-value of 0.8460 whereas $\mathrm{pH}$, catalyst dosage and initial caffeine concentration with p-value of $0.005,0.0195$ and 0.0173 , respectively, have significant effect on the degradation of caffeine, buttressing the order of effect described above.

Table 9: Results of the ANOVA for degradation of caffeine.

\begin{tabular}{|c|c|c|c|c|c|}
\hline Source & DF & Adj SS & Adj MS & F-value & 0.05 \\
\hline A & 2 & 43.56 & 21.78 & 14.68 & 0.0195 \\
\hline B & 2 & 2253.6 & 1126.78 & 0.17 & 0.0050 \\
\hline C & 2 & 146.9 & 73.44 & 0.33 & 0.0173 \\
\hline D & 2 & 270.2 & 135.1 & 0 & 0.8460 \\
\hline
\end{tabular}

In order to corroborate the region where optimum response lies, contour plot (Fig. 9) was constructed using the most significant factors in the caffeine degradation ( $\mathrm{pH}$ and caffeine concentration). The isolines on the contour plot represent distinct level of design parameter. The darker portion of the plot which is within the $\mathrm{pH}$ range of level 1 to 3 and catalyst dose of 2 to $3 \mathrm{~g} / \mathrm{L}$ represent the area where there is highest probability of finding the optimum response $(>90 \%)$. As seen from Fig. 9, the maximum of the contour plot is at level 2 for both the $\mathrm{pH}$ catalyst dosage. This indicates that at $\mathrm{pH}$ of 6 and catalyst dose of $1.5 \mathrm{gL}^{-1}$ the degradation efficiency will be greater than $90 \%$.

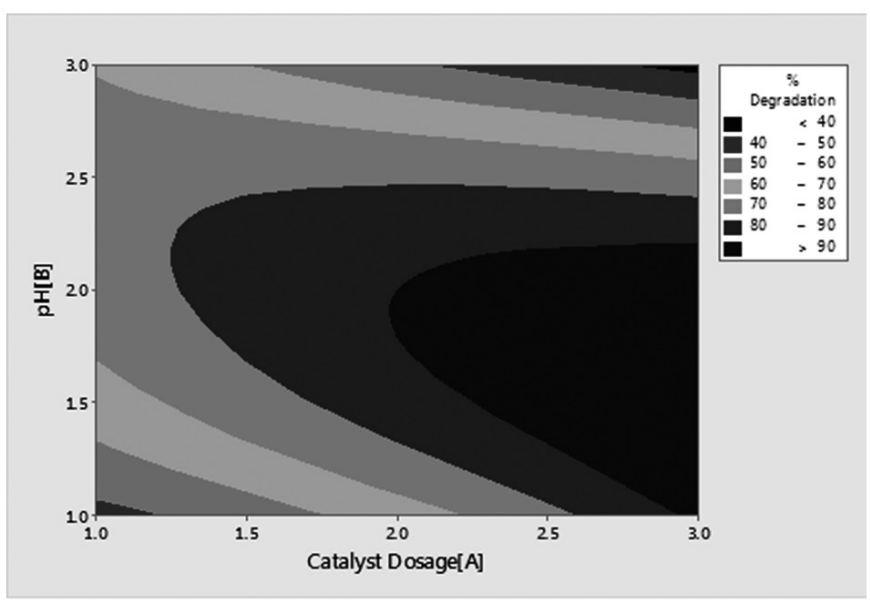
dosage

Fig. 9: Contour plot of percentage degradation versus $\mathrm{pH}$ and catalyst

\subsection{Kinetic scheme}

The effect of photolysis and bare $\mathrm{TiO}_{2}$ photocatalysis were studied and compared with the photocatalytic degradation profiles over $\mathrm{EY} / \mathrm{Ag}-\mathrm{TiO}_{2}, \mathrm{Ag}$ doped $\mathrm{TiO}_{2}$ and EY-sensitized $\mathrm{TiO}_{2}$. The results are displayed in Fig. 10. It can be observed from the figure that $\mathrm{EY} / \mathrm{Ag}-\mathrm{TiO}_{2}$, having $95 \%$ removal at 290 min (Fig. 10d), has outperformed Ag-doped $\mathrm{TiO}_{2}$ (52\% removal; Fig. 10b) and EY-sensitized $\mathrm{TiO}_{2}$ (68\%; Fig. 10c). As shown in Table 10, the caffeine degradation efficiency over the $\mathrm{EY} / \mathrm{Ag}-\mathrm{TiO}_{2}$ is higher than that of titanium dioxide nanotube ${ }^{17}$. Moreover, unlike in the removal of caffeine by ozonation ${ }^{15}$, the degradation efficiency continued to steadily increase until almost all of the original caffeine has been removed. The bare- $\mathrm{TiO}_{2}$ photocatalysis led to only $37 \%$ caffeine removal (Fig. 10e) while irradiation alone was barely inefficient caffeine removal process (Fig. 10a).

Kinetic profiles based on pseudo zero-order and pseudo first-order integrated rate equations (Eq. 8 and 9, respectively) were plotted for experiments at optimum catalyst dosage $(1.75 \mathrm{~g} / \mathrm{L}), \mathrm{pH} 5.5$ and initial caffeine concentration $(10 \mathrm{mg} / \mathrm{L})$.

$$
\begin{aligned}
& {[\text { Caffeine }]_{\mathrm{t}}=[\text { Caffeine }]_{\mathrm{o}}-k_{o}^{\prime} t} \\
& \ln [\text { Caffeine }]_{\mathrm{t}}=\ln [\text { Caffeine }]_{\mathrm{o}}-k_{1}^{\prime} t
\end{aligned}
$$

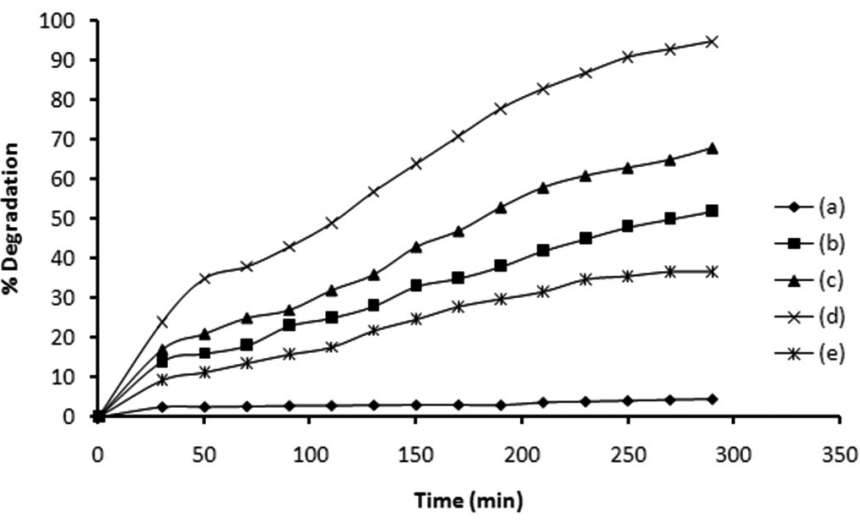

Fig. 10: Caffeine removal profiles under irradiation in presence of absence of catalyst (a) Irradiation alone (b) $\mathrm{Ag}-\mathrm{TiO}_{2}$ (c) $\mathrm{EY}-\mathrm{TiO}_{2}$ (d) $\mathrm{EY} / \mathrm{Ag}-\mathrm{TiO}_{2}$ (e) $\mathrm{TiO}_{2}$.

Where [Caffeine] is the caffeine concentration at time $\mathrm{t}$ and [Caffeine] is the initial caffeine concentration. The rate constant corresponding to each equation was obtained from the slope. Rate constant data obtained in this study is displayed by Table 10 . The degradation of caffeine over EY-Ag/TiO agreed with pseudo zero-order kinetic scheme with rate constant $(k)$ of $1.7 \times 10^{-2} \mathrm{~min}^{-}$ ${ }^{1}\left(\mathrm{R}^{2} \approx 0.99\right)$ (Fig. A-5, supplementary materials file). However we as usual with bare $\mathrm{TiO}_{2}$ consistence with pseudo first-order scheme was observed as well as improved degradation efficiency upon downsizing from $138.64 \mathrm{~nm}$ to $69.32 \mathrm{~nm}$ (Fig. A-6, supplementary materials file). However, Barndök et al. ${ }^{44}$ observed rather a decreased caffeine degradation efficiency with the downsizing of monodisperse anatase $\mathrm{TiO}_{2}$ as shown in Table 10.

\subsection{Quantum chemical account of sensitization}

In order to study the electron injection from dye to the $\mathrm{TiO}_{2}$ and the energies associated with $\mathrm{EY}$ and $\mathrm{EY}$ sensitized $\mathrm{TiO}_{2}$, density functional theory calculations were carried out with the aid of the hybrid B3LYP functional, which integrates HF and Becke exchange terms with the Lee-Yang-Parr correlation functional by using 6-31G(d) basis set. The molecular structure of the optimized geometry of the $\mathrm{EY}$ and $\mathrm{EY} / \mathrm{TiO}$, are shown in Fig. 11a The framework of the dye sensitized photocatalyst consists of $\mathrm{Ti}_{5} \mathrm{O}_{10}$ cluster attached to the carboxylic acid group of the EY molecule via a bidentate bridge. The C10-C11 bonds of both the models are 1.34505-1.3942( $\AA$ ) indicating the $\Pi$-conjugation nature of the bonds. The calculated average Ti-O bond distance $(1.97685 \AA)$ is within the range reported by past workers $(1.949 \text { to } 1.980 \AA)^{46}$. The dipole moment of the $\mathrm{EY} / \mathrm{TiO}_{2}(8.2175 \mu)$ is larger than that of $\mathrm{EY}(5.8244$ $\mu)$ which indicates increased electronegetivity due to the Ti-O bond. 
Table 10: Kinetic parameters for $\mathrm{EY} / \mathrm{Ag}-\mathrm{TiO}_{2}$ and $\mathrm{TiO}_{2}$.

\begin{tabular}{|c|c|c|c|c|c|c|c|}
\hline Titania & $\begin{array}{c}\text { Pseudo } \\
\text { first-order }\end{array}$ & & & $\begin{array}{c}\text { Pseudo } \\
\text { zero-order }\end{array}$ & & & Ref. \\
\hline & $\begin{array}{c}k_{l} \\
\left(10^{-3} \mathrm{moldm}^{-3} \mathrm{~s}^{-1}\right)\end{array}$ & $\mathrm{R}^{2}$ & $\% \mathrm{D}$ & $\begin{array}{c}k \\
\left(10^{-3} \mathrm{~min}^{-1}\right)\end{array}$ & $\mathrm{R}^{2}$ & $\% \mathrm{D}$ & \\
\hline $\mathrm{EY} / \mathrm{Ag}-\mathrm{TiO}_{2}(69.32 \mathrm{~nm})$ & 3 & 0.956 & & 1.7 & 0.988 & 95 & This study \\
\hline Bare $\mathrm{TiO}_{2}(138.64)$ & 6 & 0.965 & & 1.5 & 0.934 & 37 & This study \\
\hline $\mathrm{NF}-\mathrm{TiO}_{2}(50 \mathrm{~nm})$ & 14.6 & - & 77 & - & - & & 44 \\
\hline $\mathrm{NF}^{-\mathrm{TiO}_{2}}(300 \mathrm{~nm})$ & 6.56 & - & 32 & - & - & & 44 \\
\hline $\mathrm{TiO}_{2}$ nanotube $(10 \mathrm{~nm})$ & - & - & 51 & - & - & & 17 \\
\hline
\end{tabular}

(a) Optimized geometry:

(i) EY

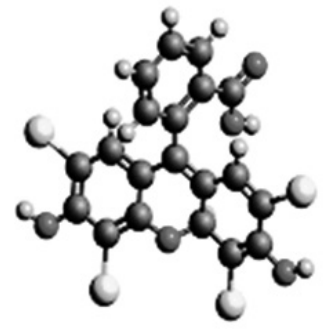

(ii) EY sensitized titania

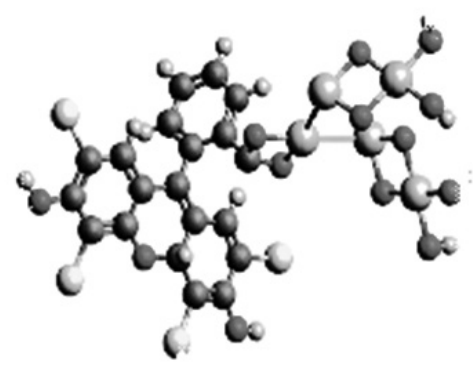

(b) Frontier molecular orbitals of EY:

(i) $\mathrm{HOMO}$

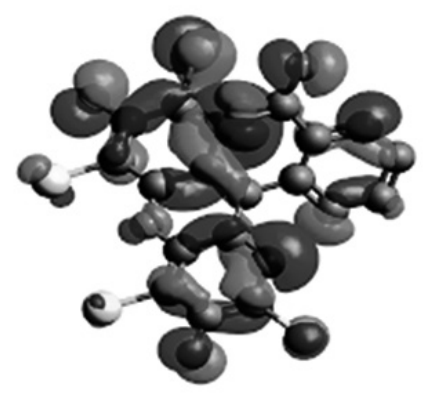

(ii) LUMO

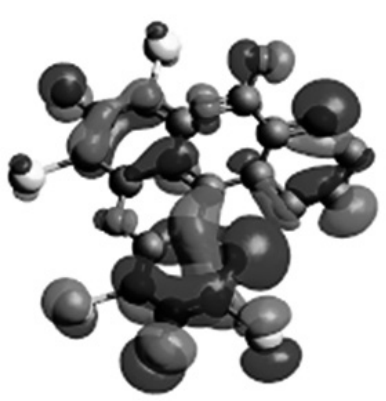

(c) Frontier molecular orbital of E osin yellow adsorbed on $\mathrm{TiO}_{2}$

(i) HOMO

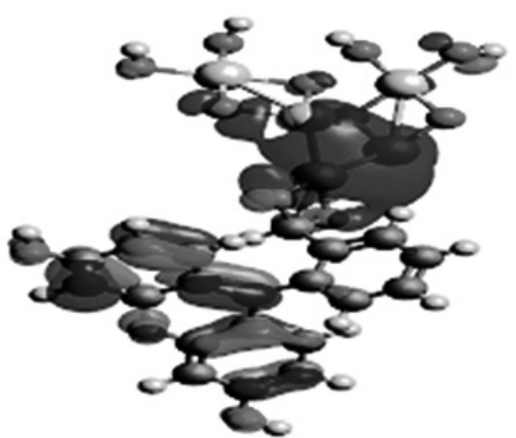

(ii) $\mathrm{LUMO}$

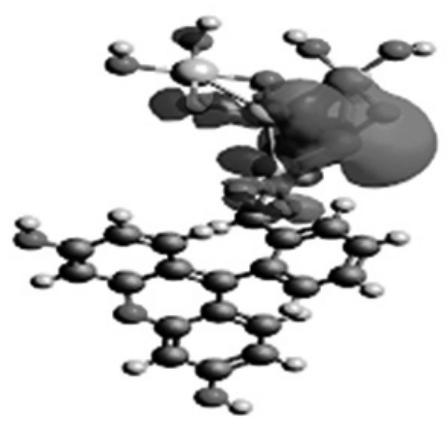

Fig. 11: (a) Optimized geometry of Eosin $\mathrm{Y}$ and $\mathrm{EY} / \mathrm{Ag}-\mathrm{TiO}_{2}$, (b) Frontier molecular orbitals of Eosin Y (c) Frontier molecular orbitals of $\mathrm{EY} / \mathrm{Ag}-\mathrm{TiO}_{2}$. 
The frontier molecular orbital of the $\mathrm{EY}$ and $\mathrm{EY} / \mathrm{TiO}$ are shown in Fig. 11b and Fig. 11c. As seen from the frontier molecular orbitals of the EY model, the electronic distribution of the HOMO and LUMO orbitals are delocalized over $\Pi$-conjugation system of the three benzene rings and the highest electron density centered on the carboxylic acid functional group. The high electron density on the carboxyl functional group indicates the ease with which electrons can be injected to conduction band of the semiconductor photocatalyst. Generally speaking, for electrons to be effectively injected into the conduction band of the semiconductor photocatalyst, the LUMO eigenvalue of the dye molecule most be sufficiently more negative than the conduction band edge of $\mathrm{TiO}_{2}(0.5$ V) ${ }^{46}$. The eigenvalue for the HOMO and LUMO orbitals of the EY molecule were -0.24944 and $-0.7246 \mathrm{eV}$ while for the Eosin Y-sensitized photocatalyst model these were $-0.1511 \mathrm{eV}$ and -0.1827 , respectively. It can be readily seen that, the energy gap $(\Delta \mathrm{E})$ between the HOMO and LUMO is larger in the case of the EY sensitized catalyst than the bare $\mathrm{TiO}$ which implies the ease with which electrons can be injected into conduction band of the $\mathrm{TiO}_{2}$ from the $\mathrm{EY}$ dye. The energy gap in the case of the sensitized catalyst is less than $0.5 \mathrm{eV}$, thus falling within the range for molecules with unusual electronic properties such as intramolecular electron transfer in solution ${ }^{47}$ and perhaps effective sensitization as in the present case.

Table 11: Excitation wavelength, energy and oscillator strength of main transition of EY and $\mathrm{EY} / \mathrm{Ag}-\mathrm{TiO}_{2}$.

\begin{tabular}{|c|c|c|c|}
\hline Model & $\begin{array}{c}\text { Wavelength } \\
(\mathrm{nm})\end{array}$ & Energy(eV) & $\begin{array}{c}\text { Oscillator } \\
\text { strength }(f)\end{array}$ \\
\hline $\mathrm{EY}$ & 507 & 2.445759 & 0.1116 \\
\hline & 412 & 3.009709 & 0.0928 \\
\hline & 265 & 4.679245 & 0.0252 \\
\hline & 247 & 5.020243 & 0.0061 \\
\hline $\mathrm{EY}_{-} \mathrm{TiO}_{2}$ & 844 & 1.469194 & 0.0071 \\
\hline & 549 & 2.258652 & 0.0052 \\
\hline & 426 & 2.910798 & 0.0375 \\
\hline & 298 & 4.161074 & 0.0500 \\
\hline
\end{tabular}

On the basis of optimized ground state geometries (Fig. 11a), absorption spectra of EY and EY-TiO, were calculated by DFT/B3LYP method. The results are shown in Table 11 . The table shows the first optically excited transition of Eosin $\mathrm{Y}$ dye and Eosin Y-sensitized $\mathrm{TiO}$ and the oscillator strength for singlet-singlet excitations. The most probable transitions were determine based on the value of the oscillator strength $(f)$. Table 11 reveals the advantage of the sensitised $\mathrm{TiO}_{2}$ to absorb over the range of 298 to $844 \mathrm{~nm}$ which predicts extended absorption beyond the visible region of the electromagnetic spectrum. This range brackets the wavelength of maximum absorption of EY (507 nm) determined in this study.

\section{CONCLUSION}

Visible light photoresponsive catalyst with increased surface and reduced particle sizes was successfully synthesized by silver doping and dye sensitization of a commercial $\mathrm{TiO}_{2}$ brand. The degradation of caffeine over this catalyst was remarkable ( $97 \%$ ), but $\mathrm{pH}$ constrained. The sensitization of $\mathrm{Ag}-\mathrm{TiO}$, resulted in amorphousness and downsizing of the precursor $\mathrm{TiO}_{2}$ particles. Results showed the capacity of the catalysts to absorb the entire range of visible light spectrum.

\section{ACKNOWLEDGEMENT}

Muktar Ibrahim thankfully acknowledges the constructive criticisms of members of Gaya's research group of the Department of Pure and Industrial Chemistry, Bayero University, Kano, during his days as student.

\section{REFERENCES}

[1] C. Indermuhle, M.J. Martín de Vidales, C. Sáez, J. Robles, P. Cañizares, J.F. García-Reyes, A. Molina-Díaz, C. Comninellis, M.A. Rodrigo, Chemosphere. 93, 1720, (2013)

[2] H.J. Souza, C.B. Moyses, F.J. Pontes, R.N. Duarte, C.E. Sanches da Silva, F.L. Alberto, U.R. Ferreira, M.B. Silva, Mol. Cell. Probes. 25, 231, (2011)
[3] C. Xu, L. Chen, L. You, Z. Xu, L.F. Ren, K.Y.-H. Gin, Y. He, W. Kai, Environ. Sci.: Processes Impacts. 20, 1030, (2018)

[4] S. Weigel, J. Kuhlmann, H. Hühnerfuss, Sci. Total Environ. 295, 131 , (2002)

[5] W.A. Cabrera-Lafaurie, F.R. Román, A.J. Hernández-Maldonado, J Hazard. Mater. 282, 174, (2014)

[6] O.M. Couto Jr, I. Matos, I. Maria da Fonseca, P.A. Arroyo, E. Antônio da Silva, M.A.S. Dornellas de Barros, Can. J. Chem. Eng. 93, 68 (2015)

[7] L.P. Padhye, H. Yao, F.T. Kung'u, C.-H. Huang, Water Res. 51, 266 , (2014)

[8] P. Wang, Z. Guan, Q. Li, J. Yang, J. Mater. Sci. 53, 774, (2017)

[9] R. Rosal, A. Rodríguez, J.A. Perdigón-Melón, A. Petre, E. García-Calvo, M.J. Gómez, A. Agüera, A.R. Fernández-Alba, Chemosphere 74, 825 (2009)

[10] O. Ganzenko, N. Oturan, D. Huguenot, E.D. van Hullebusch, G. Esposito, M.A. Oturan, 156, 987, (2015)

[11] A.O. Ibhadon, F.H. Paul, Catalysts 3, 234, (2013)

[12] N. Nakada, H. Shinohara, A. Murata, K. Kiri, S. Managaki, N. Sato, H. Takada, Water Res. 41, 4373, (2007)

[13] N. Vieno, T. Tuhkanen, L. Kronberg, Water Res. 41, 1001, (2007)

[14] M. Klavarioti, D. Mantzavinos, D. Kassinos, Environ. Int. 35, 402, (2009)

[15] R. Rosal, A. Rodríguez, J.A. Perdigón-Melón, A. Petre, E. García-Calvo, M.J. Gómez, A. Agüera, A.R. Fernández-Alba, Chemosphere 74 (2009) 825-831. https://doi.org/10.1016/j.chemosphere.2008.10.010.

[16] U.I. Gaya, Heterogeneous Photocatalysis Using Inorganic Semiconductor Solids, Springer, Dordrecht, 2014.

[17] M.K. Arfanis, P. Adamou, N.G. Moustakas, T.M. Triantis, A.M. Kontos, P. Falaras, Chem. Eng. J. 310, 525, (2017)

[18] J. Matos, B. Llano, R. Montaña, P.S. Poon, M.C. Hidalgo, Environ. Sci. Pollut. Res. 25, 18894, (2018)

[19] P. Chowdhury, J. Moreira, H. Gomaa, A.K. Ray, Ind. Eng. Chem. Res. 51, 4523, (2012)

[20] X. Li, J.-L. Shi, H. Hao, X. Lang, Appl. Catal., B. 232, 260, (2018)

[21] D. Chatterjee, A. Mahata, J. Photochem. Photobiol. A. 165, 19, (2004)

[22] M. Grätzel, Inorg. Chem.44, 6841, (2005)

[23] S. Rengaraj, X.Z. Li, J. Mol. Catal. A: Chem. 243, 60, (2006)

[24] H. Ran, J. Fan, X. Zhang, J. Mao, G. Shao, Appl. Surf. Sci. 430, 515, (2017)

[25] P. Wang, L. Zong, Z. Guan, Q. Li, J.Yang, Nanoscale Res. Lett. 1, (2018)

[26] A. Yusuf, U. Gaya, Nanochem. Res. 3, 29, (2018)

[27] R.A. Spurr, H. Myers, Anal. Chem. 29, 760, (1957)

[28] K.P.D.A. Savio, D. Starikov, A. Bensaoula, R. Pillai, L.L. de La Torres Garcia, C.R. Hernández, Ceram. Int. 38, 3529 (2012)

[29] Y. Zhang, Q. Li, Solid State Sci. 16, 16, (2013)

[30] K. Lalitha, J.K. Reddy, M.V.P. Sharma, V.D. Kumari, M. Subrahmanyam, Int. J. Hydrogen Energy 35, 3991, (2010)

[31] L. Wen, B. Liu, C. Liu, X. Zhao, Journal of Wuhan University of Technology-Mater. Sci. Ed. 24, 258, (2009)

[32] K. Selvam, M. Swaminathan, J. Mol. Catal. A: Chem. 351, 52, (2011)

[33] S. Sakthivel, M.V. Shankar, M. Palanichamy, B. Arabindoo, D.W Bahnemann, V. Murugesan, Water Res. 38, 3001, (2004)

[34] M. Nag, D. Guin, P. Basak, S.V. Manorama, Mater. Res. Bull. 43, 3270, (2008)

[35] K. Selvam, M. Swaminathan, $R S C A d v .2,2848$, (2012)

[36] M.R. Hoffmann, S.T. Martin, W. Choi, D.W. Bahnemann, Chem. Rev. 95, $69,(1995)$

[37] D.A.H. Hanaor, C.C. Sorrel, J. Mater. Sci. 46, 855, (2011)

[38] B. Ohtani, J. Photochem. Photobiol. C. 11, 157, (2010)

[39] B. Ohtani, Chem. Lett. 37, 217, (2008)

[40] J. Coates in Encyclopedia of Analytical Chemistry, R.A. Meyers eds. Wiley \& Sons Ltd, Chichester, 2000; pp.10815-10837.

[41] O. Carp, C.L. Huisman, A. Reller, Prog. Solid. State Chem. 32, 33, (2004) Eng. J. 310, 525, (2017)

[42] I. Asiltürk, H. Akkuş, Measurement. 44, 1679, (2011)

[43] R.R.N. Marques, M.J. Sampaio, P.M. Carrapi, C.G. Silva, T.S. Morales, G. Drazic, J.L. Faria, A.M.T. Silva, Catal. Today. 209, 108, (2013)

[44] H. Barndõk, M. Peláez, C. Han, W.E. Platten III, P. Campo, D. Hermosilla A. Blanco, D.D. Dionysiou, Environ. Sci. Pollut. Res. 20, 3582, (2013)

[45] S.-D. Mo, W.Y. Ching, Phys. Rev. B: Condens. Matter Mater. Phys. 51, $13023,(1995)$

[46] C. Dette, M.A. Pérez-Osorio, C.S. Kley, P. Punke, C.E. Patrick, P. Jacobson, F. Giustino, S.J. Jung, K. Kern, Nano Lett. 14, 6533, (2014)

[47] D.F. Perepichka, M.R. Bryce, Angew. Chem. Int. Ed. 44, 5370, (2005) 